\title{
DEVELOPMENT OF INTERGRANULAR CRACKING AND RELAXATION OF STRESS IN DEEP CRYSTALLINE ROCK OF EARTH CRUST AS RESULT OF PHYSICO-CHEMICAL INFLUENCE OF WATER
}

\author{
M.Z.Abdrakhimov, E.I.Kouznetsova \\ Research Industrial Company GERS, Apt. 62, d.4, 2-nd Pereulok \\ Truzhennikov, 119121 Moscow Russia \\ V.Yu.Traskin \\ Moscow Lomonosov University, Russia
}

Many of fundamental questions in the Earth sciences are related to fluids. Despite the importance of fluid - rock interactions in many geologic processes, there is still a lack of knowledge as regards the behavior of fluids at depth, especially in situations involving both mechanical and physico-chemical impact of a liquid phase. The current tendency to consider these two aspects of the solid - liquid interaction without taking into account their interplay leads to an understatement of the role of fluids when they are present in small amounts, do not interact chemically with surrounding minerals to any appreciable extent and do not dissolve them. Therefore they are not thought to affect the structure and properties of enveloping rocks and the role of fluids is often neglected.

However, it is nowadays a well established fact that surface (or interface) phenomena which are extremely sensitive even to trace concentrations of certain chemical compounds must be taken into consideration when analyzing mechanical behavior and structure evolution of rocks as well as any other solids without exception. For this purpose one can use the ideas and experimental methods of the physico-chemical mechanics put forward by P.A. Rehbinder and developed in the course of last decades in particular as applied to the Earth sciences. This approach proved to be successful in explaining many cases of premature failure or structural degradation of solids relating them to adsorption-induced strength decrease or stress corrosion.

The nature of surface-active agents is specific to any given type of solids. In the case of rocks, by far the most important component of aggressive fluids is the water.

In the cases when the grain boundary free energy $\mathrm{s}_{\mathrm{GB}}$ is sufficient to produce the intergranular wetting, the relative free energy threshold beyond which the boundaries are permeable is known as Gibbs-Smith condition [Gibbs J.W., 1982]:

$$
2 \delta_{\mathrm{SL}}<\delta_{\mathrm{GB}}
$$

where the subscripts GB and SL mean grain boundary and solid / liquid .

The spontaneous liquid penetration along grain boundaries was observed on some metallic systems, on water - rock salt at the room temperature, water - carbonate and silicate rocks in special temperature and stress conditions

A large number of data obtained at the Kola Superdeep well give evidence that below 7-8 $\mathrm{km}$ rocks in-situ around the hole are in state of volume discompaction.

Our experimental study have demonstrated that the surface activity of water as the principal constituent part of the drilling fluid, combined with elevated temperatures and differential stresses, contributes to the development of intergranular microcracks under conditions for the lower part of Kola Superdeep Well.

For this purpose, we have employed a piston-cylinder testing apparatus allowing to perform triaxial tests of cylinder-shaped specimens $(15 \times 30 \mathrm{~mm})$ in various liquid environments (water, drilling fluid, crude oil, acetone), within $300^{\circ} \mathrm{C}$ temperature range and at confining pressures up to $300 \mathrm{MPa}$ and axial loads until specimen failure. Accordingly we can simulate stress and temperature condition of state of rock in the hole at the large depth. For experiments we have took analogs of 
rock core Kola well: massive amphibolite and gneiss without microcraks. Before and after testing we measured density, porosity, compressive and shear wave and prints on photographic paper visualizing microcracks distribution.

Amphibolite and gneiss specimens were exposed to water or drilling fluid at various temperatures, confining pressures and differential loads. We discovered that above $100^{\circ} \mathrm{C}$ grain boundaries into rock open, forming intergranular microcracks, after 3 hours exposure . Axial deviator stress increase this effect and bring to appearance of transect cracks subparalleled to main stress (Fig.1-2).

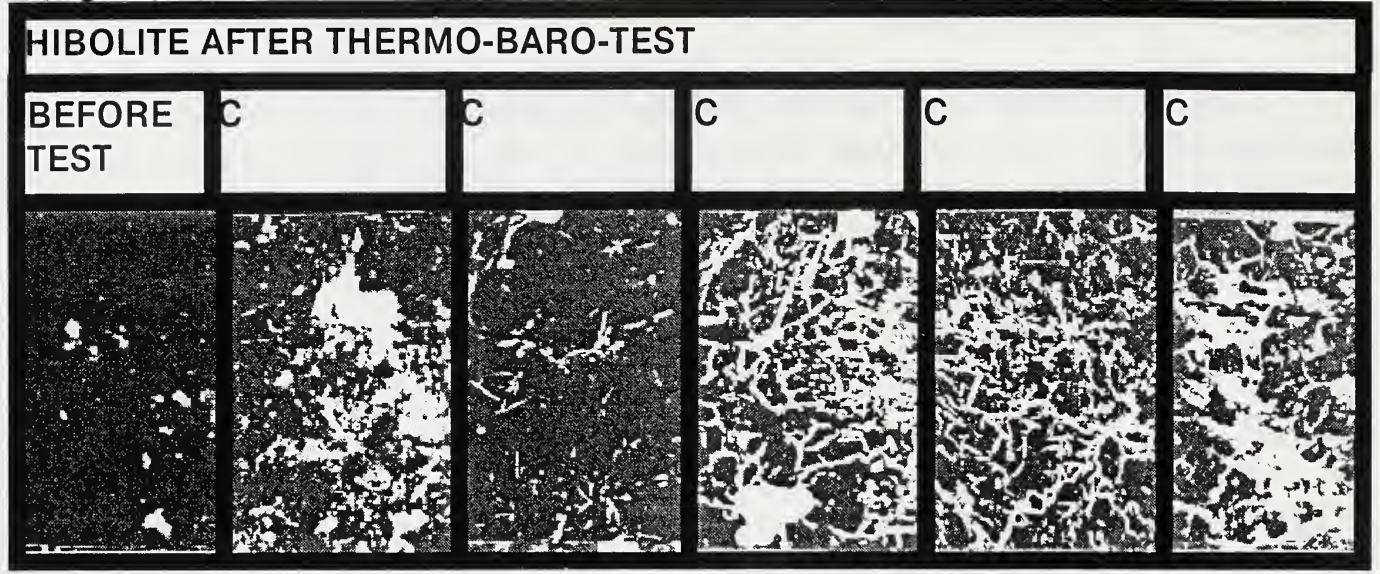

Fig. 1. Print images of open microcracks on surface of amphibolite (rocks - analogs of core SG-3) before $(1,7)$ and after tests during 3 hours in thermo-baro-aparatus, under hydrostatic pressure of $100 \mathrm{MPa}$ and temperature:100;150;200;250 $\mathrm{C}$

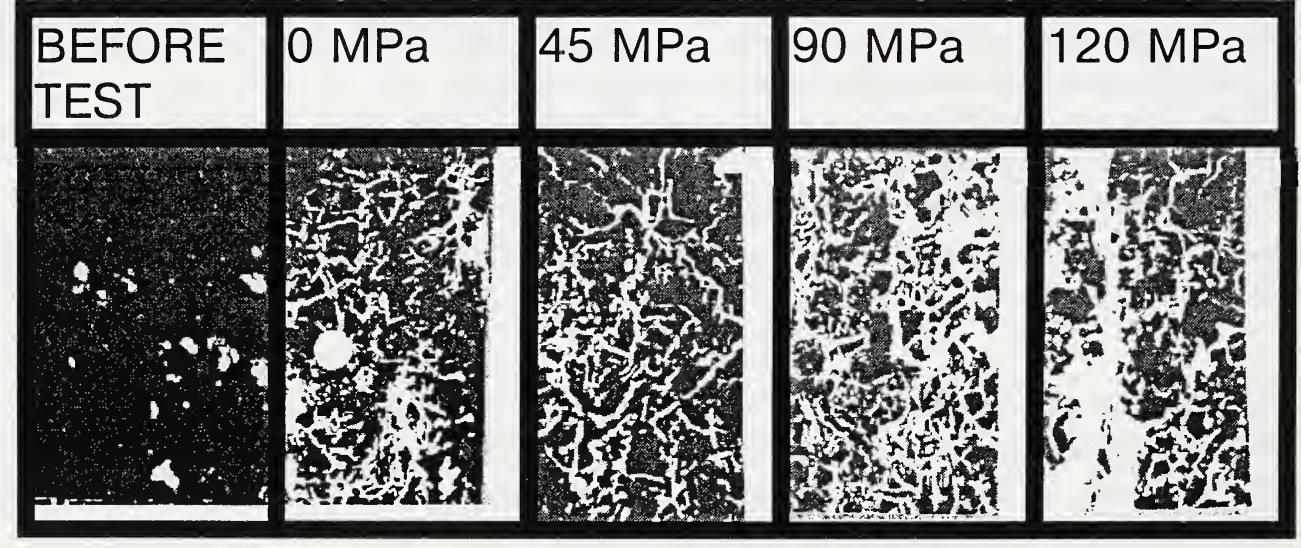

Fig. 2. Print images of open microcracks on surface of amphibolite (rocks - analogs of core SG-3) before (1) and after tests during 3 hours in thermo-baro-aparatus, under temperature $2000 \mathrm{C}$, hydrostatic pressure $100 \mathrm{MPa}$ and deviator pressures: 0 (2); 45 (3); 90 (4); 120 (5) MPa

No one of these factors acting separately affects grain boundaries, neither does the combination of differential stresses and high temperature over the range investigated.

At the same time worth noting is, that repeatable circular mechanical stress action leads to intergranular water penetrating even under low temperature. This was provided a special test series, held for the purpose of natural ventilating processes. Samples of different rock types 
passed through boiling once a day, with following freezing. After 60 cycles (days) great changes appeared (reduce of $\mathrm{Vp}$ and $\mathrm{Vs}$, increase of wave attenuation and porosity) and intergrainular cracking formed in ultrabasic and basic cores (piroxenite, gabbro, amphibolite). Acid cores (granitegneiss, granites) have not changed. It is important, that intergranular cracks grate, formed in piroxenite, joined primitive sulphide grains, what certifies inherited character of bounds openning, by which before using the same mechanism natural hydrothermal fluids flowed with subsequent sulfides production.

Above stated data allows to determine condition diapason, in which crystalline rocks had to be permeable in relation to natural and technical fluids.

According to our experimental data intergranular destruction development because of voluntary penetration of water along grain boundaries must start by the temperature over $100 \mathrm{C}^{\circ}$. This was confirmed during SD-3 core studies. On the depth of $7-12 \mathrm{~km}$, where temperature changes from 100 to $200^{\circ} \mathrm{C}$, intergrain destruction is mostly displayed with manifest increase with depth

Practical use of the given results is possible in technological processes, connected with disintegration of kimberlite at extraction of diamonds. 